\title{
NASA 2018 Green Propulsion Roadmap
}

\author{
$65^{\text {th }}$ JANNAF Propulsion Meeting \\ Long Beach, CA \\ May 21-24, 2018
}

Green Propulsion Working Group (GPWG):

Dan Cavender/MSFC (Chair)

Bill Marshall/GRC (Co-Chair)

Andrew Maynard/GSFC 


\section{Presentation Overview}

- Overview of Roadmap Document

- Green Propellant Working Group (GPWG)

- Strategic Goals of GPWG

- Definition of Green Propellants

- 2016 Inter-Agency Roadmap

- Overview of Roadmap Technology Development Areas (TDA's)

- Alignment to NASA Technology Investment Strategies

- Overview of Infusion Opportunities

- Role of Partnerships

- Summary 


\section{Outline of Roadmap Document}

Sections:

1. Introduction

2. Purpose

3. Scope

4. Background

1) Green Propulsion Working Group

2) Strategic Goals of the Green Propulsion Working Group (GPWG)

3) Definition of Green Propulsion

4) 2016 Inter-Agency Roadmap

5) Alignment to NASA Technology Roadmaps

6) Investments to Date

5. Green Propulsion Technology Development Areas (TDA's)

6. Identification of Potential NASA Infusion Opportunities

7. Role of Partnerships

8. Summary

Appendix A. Strategic Technology Investment Guides and Plans Appendix B. Acronyms

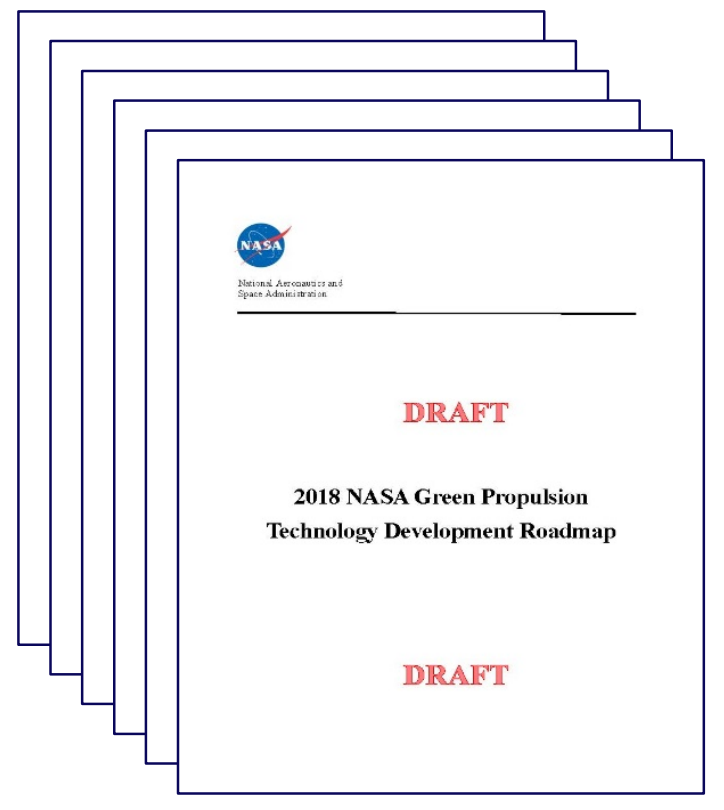




\section{Green Propulsion Working Group}

- The Green Propulsion Working Group (GPWG) is a technical guidance working group formed April 2017 under the Agency's Capability Leadership Team

- The GPWG was tasked with recommending an agency road map and providing guidance to NASA on green propulsion technology development and infusion

- The GPWG's efforts focus on ionic liquid propellants and related technologies

- The GPWG was chartered with three representatives from NASA Centers currently exploring green propulsion technologies

- As other Centers may explore programs that utilize green propulsion, membership of the working group can be expanded to include more interested parties

- Working group also solicits and coordinates with other government agencies (e.g. AFRL, MDA) 


\section{GPWG within NASA Capability Leadership Team}

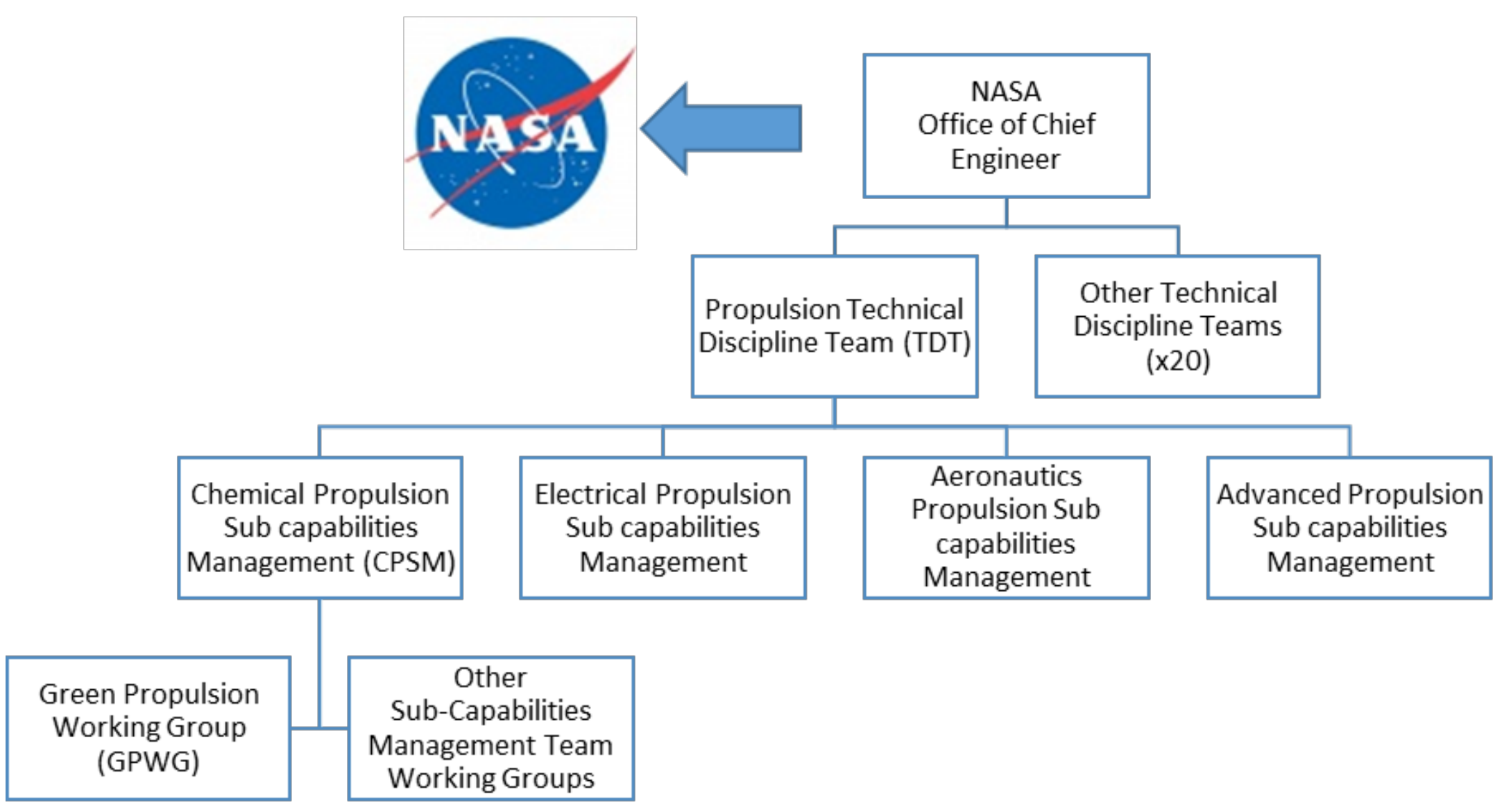




\section{Strategic Goals}

- As part of its chartered role, and in order to maximize the Agency return on investments, the GPWG seeks to establish the following strategic goals

- STRATEGIC GOAL 1: Establish Agency Vision for Green Propulsion

- Develop a roadmap for green propulsion technology development

- $\quad$ STRATEGIC GOAL 2: Provide Guidance to Focus Energy and Resources

- Continually monitor green propulsion technology efforts for awareness and serve in an advisory role to direct and support Agency efforts to advance green propulsion technologies

- STRATEGIC GOAL 3: Knowledge Archiving, Distribution and Utilization

- A centralized Agency controlled green propulsion technologies document \& knowledge repository should be constructed 


\section{Definition of Green Propellants}

- Green propellants are characterized by their relatively benign handling characteristics relative to hydrazine $\left(\mathrm{N}_{2} \mathrm{H}_{4}\right)$, and their benign exhaust products

- The Green Propulsion Roadmap focuses on ionic liquid propellants and related technologies (e.g. catalysts, thrusters, etc.) which are seen as direct or near-direct replacements for hydrazine

- These include various blends of hydroxylammonium nitrate (HAN) and ammonium dinitramide (ADN) based formulations, and shall include both monopropellant and bipropellant applications

- While monopropellant applications are the current focus of this roadmap and most development efforts, applications to bi-propellant systems are also considered of interest to the agency and technology needs for those systems will be addressed similarly. 


\section{Inter-Agency Roadmap}

- In 2015, JANNAF hosted a Technical Interchange Meeting (TIM) on Green Monopropellant Alternatives to Hydrazine (GMAH)

- Included both Government and non-Government contributions on the State-of-the-Art in Green Propulsion Technology

- Following the TIM, a Government-only session (USAF/AFRL/NASA/MDA/DLA) reviewed and identified remaining technical gaps in Green Propulsion

- In 2016, an inter-agency team (AFRL/NASA/MDA) worked together to develop an informal inter-agency "roadmap" based on the outcome of the TIM

- Approach consisted of near-term, mid-term, and long-term technology advancement areas, approaching incrementally larger thrust classes 


\section{Inter-Agency Identified Technology Gaps}

The Inter-Agency Working Group identified a series of technology gaps after presentations by various government and industry partners during the main portion of the GMAH TIM. Those technology gaps identified were:

$>$ Ignition power and techniques - catalyst systems can be heavier in mass than non-catalytic systems and require significant power to utilize.

$>$ Throughput - existing green propellant thrusters have only demonstrated a fraction of lifetime compared to existing state-of-the-art hydrazine thrusters. The hotter combustion environment, steep thermal transients, and corrosive intermediate species of combustion are believed to reduce overall thruster and catalyst lifetimes.

$>$ Plume modeling - impact of continuum and rarified flow effects, effluents of thrusters/propellants, and impact on nearby spacecraft surfaces are not well understood.

- Materials properties -material and thermal property data on iridium, rhenium and/or other refractory metals, particularly at the elevated temperatures experienced by green propellant thrusters, is lacking. Material compatibility, particularly for soft-goods, is not well understood. 


\section{Inter-Agency Identified Technology Gaps}

- $\quad$ Response time - required pre-heat times and ignition delays seen in state-of-theart green propellant thrusters are longer than state-of-the-art hydrazine thrusters.

- New propellant formulations - other higher performing formulations of green propellants are being developed, and have not been evaluated to the same degree as AF-M315E or LMP-103S. The trade between combustion temperature (and thereby thruster/catalyst life) and performance by altering the blend ratios of propellants isn't well understood. Comprehensive standards for how propellants are made/blended (similar to existing propellant MIL-specs) are non-existent.

- Manufacturing techniques and cost - current material systems used in green propulsion systems are expensive and difficult to come by. Manufacturing methods are more expensive relative to hydrazine thruster systems.

- Propellant performance modeling - analysis codes for more predictive analysis of behavior and decomposition/combustion process are lacking or non-existent.

- Propellant supply - current propellant formulations are either foreign sourced or contain constituents that are foreign sourced. No dedicated logistical supply chain exists. 


\section{Inter-Agency Roadmap}
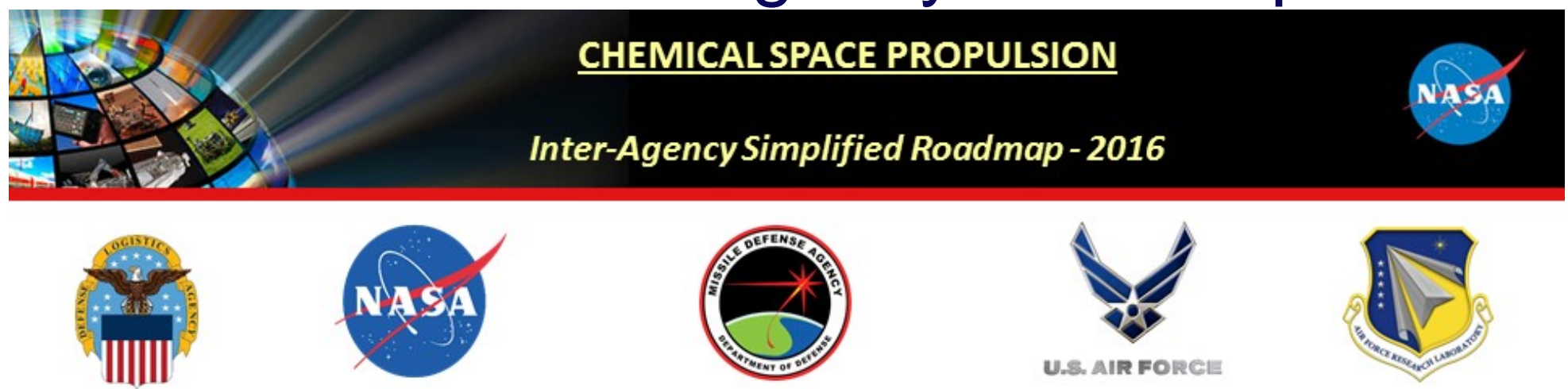

NEAR-TERM PRIORITY

Over the next 3 years, concentrate on

the high priority tasks which helps to enable larger scale thrusters with focus on maturing up to the $22-\mathrm{N}$ class
- Propellant Throughput (duty cycles, catalyst/thruster life) - Plume Measurements (anchor models, effects on optical systems \& solar array)

- Transient Thermal Analysis (non-CFD, effects on soak back) - Valve work (configuration, seals, operation)

- Decomposition Chemistry (sooting, corrosion, modeling \& testing) - Power Consumption (catbed heating and ops impact for human missions)

\section{MID-TERM PRIORITY}

Over the next 3-7 years, focus on the medium priority tasks and deliver a $110-\mathrm{N}$ thruster that has mutual benefit to both NASA and DoD
- M\&P Investigations (bladder/material compatibility) - Performance Trades (propellant variation, scaling effects)

- Loading Demonstrations (at launch facilities)

- System Modeling (influenced by CFD and plume data) - CFD (kinetics)

- Storage \& Transport (of loaded prop)

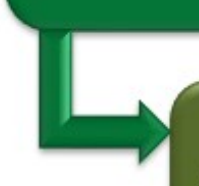

\section{LONG-TERM PRIORITY}

Over the next 7-10 years, deliver a $440-\mathrm{N}$ thruster for NASA and commercial satellite providers \& develop alternate applications
- Contamination (purity/quality impacts)

- High Radiation Flux (material selection)

- Alternate Applications (APU/EPU, etc.)
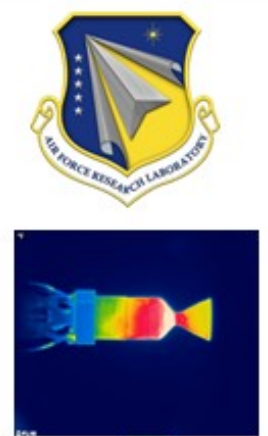

* Presented in graphical form at $2016 \mathrm{JPC}$ 


\section{Inter-Agency Roadmap}

\begin{tabular}{|c|c|c|c|}
\hline & Near-Term Priority & Mid-Term Priority & Long-Term Priority \\
\hline Timeframe & Over next 3 years & 3-7 years & $7-10$ years \\
\hline $\begin{array}{l}\text { Thrust class } \\
\text { target }\end{array}$ & Up to $22-\mathrm{N}$ & Up to $110-\mathrm{N}$ & $\begin{array}{l}\text { Up to } 440-\mathrm{N} \& \\
\text { alternative } \\
\text { applications }\end{array}$ \\
\hline $\begin{array}{l}\text { Primary } \\
\text { Technology } \\
\text { Advancement } \\
\text { Areas }\end{array}$ & \begin{tabular}{|l} 
- \\
Propellant throughput \\
(duty cycles, \\
catalyst/thruster life) \\
Plume measurements \\
(anchor models, effects on \\
spacecraft optical systems \\
or solar arrays) \\
- Transient thermal analysis \\
(non-CFD, effects on \\
soak-back temperatures) \\
Valve work \\
(configurations, seals, \\
operation) \\
Decomposition chemistry \\
(sooting, corrosion, \\
modeling \& testing) \\
Power consumption \\
(catbed heating, \\
operational impacts for \\
human missions)
\end{tabular} & $\begin{array}{ll}\text { - } & \text { Materials and } \\
\text { property (M\&P) } \\
\text { investigations } \\
\text { (bladder/material } \\
\text { compatibility) } \\
\text { - } \text { Performance } \\
\text { trades (propellant } \\
\text { variations, scaling } \\
\text { effects) } \\
\text { - Loading } \\
\text { demonstrations } \\
\text { (at launch } \\
\text { facilities) } \\
\text { - System modeling } \\
\text { (influenced by } \\
\text { CFD and plume } \\
\text { data) } \\
\text { CFD (kinetics) } \\
\text { Storage and } \\
\text { transport (of } \\
\text { loaded propellant) }\end{array}$ & $\begin{array}{ll}\text { - } & \begin{array}{l}\text { Contamination } \\
\text { (purity/quality }\end{array} \\
\text { impacts) } \\
\text { - }\end{array}$ \\
\hline
\end{tabular}




\section{Overview of Technology Development Areas (TDA's)}

- The NASA Green Propulsion Working Group reviewed the work of the 2016 Inter-Agency Working Group, and concurs that the identified technical gaps and technology development areas are still relevant and necessary to see green propulsion technology advanced

- The GPWG recommends the 2016 roadmap be adopted as baseline for NASA needs, with some additions

- The focus of the 2016 inter-agency roadmap was primarily on the thruster technology. The Agency must also invest in understanding the broader propulsion system-level technology gaps in parallel.

- Timeframes are considered suggested from a priority standpoint, but are also flexible as some efforts will need to occur in the nearer term or concurrently in order to meet specific mission requirements

- The GPWG developed 2018 roadmap breaks down the technology development goals into Technology Development Areas (TDA's), and identifies the near-, mid, and long-term subgoals within those areas. Those TDA's are:

- Thruster Hardware Development

- Modeling \& Tools Development

- Materials Properties and Compatibility

- Propellant Development 


\section{Technology Development Areas (TDA's)}

\section{TDA-01: Thruster Hardware Development}

1. Improve Propellant Throughput (near-term)

2. Reduce Ignition Power Requirements (near-term)

3. Develop Supporting Hardware (near to mid-term)

4. Improve Manufacturing Techniques \& Cost (mid-term)

\section{TDA-02: Modelling \& Tools Development}

1. Plume Models (near-term)

2. Catalytics \& Decomposition Chemistry (near-term)

3. Transient Thermal Analysis (near-term)

4. Propellant performance modeling (mid to long-term) 


\section{Technology Development Areas (TDA's)}

\section{TDA-03: Materials properties and compatibility}

1. Identify and increase system material compatibility database, including compatible softgoods (e.g. seals, bladders, etc.) (near to mid-term)

2. Generate a green propulsion database, such as inclusion of data into NASA's Materials And Processes Technical Information System (MAPTIS) database (mid-term)

3. Identify impacts of high radiation flux onto system components (long-term)

\section{TDA-04: Propellant Development}

1. Improve and Develop Propellant Supply Base (near-term)

2. Quantify and Expand Database of Propellant Properties(near to mid-term)

3. Explore New Propellant Formulas (mid to long-term)

4. Explore Alternate Applications (long-term) 


\section{Alignment to NASA Technology Investment Strategies}

- When considering a strategic approach to space technology investment, NASA has several policy documents to provide guidance

- NASA's Strategic Space Technology Investment Plan (2012)

- NASA's 2014 Strategic Plan

- NASA's Technology Roadmaps (2015)

- These are often a required reference in responses to Agency solicitations to show alignment to NASA strategic goals and plans

- Additionally, two other sources were considered

- National Research Council (NRC) NASA Space Technology Roadmaps and Priorities: Restoring NASA's Technological Edge and Paving the Way for a New Era in Space

- "Green Propulsion Advancement: Challenging the Maturity of Monopropellant Hydrazine" AIAA JPP article by Sackheim and Masse

- The Green Propellant Working Group reviewed these documents and developed the 2018 Green Propulsion Roadmap in such a manner to ensure compliance and alignment to these other strategic documents 


\section{Overview of Infusion Opportunities}

- As with all Agency technology developments, the goal is the infusion of the technology into space flight opportunities

- The NASA flight opportunities in the near term are most likely going to be with science focused missions as well as the SmallSat/CubeSat community

- For these missions the thruster sizes of interest are predominantly the $100-\mathrm{mN}$ to $22-\mathrm{N}$ classes

- The Department of Defense (DoD) and other Government Agencies are also interested in green propulsion development, and there are unique infusion opportunities there, as well

- There are notable differences to the applications of the technology to the missions DoD might pursue vs. those that NASA might pursue

- In general, the rapid response, high-impulse applications of DoD uses tend to require higher performance propellant blends which lead to hotter combustion temperatures, shorter catalyst lifetimes and more exotic materials, whereas applications for NASA are more tolerant of systems that require longer pre-heat times and tolerant of slower response, but which need more robust components where hardware can be expected to "coast" for months to years between use

- While these agency needs appear divergent, the development needed to serve each mission type is complimentary, and several TDAs contribute to advancement for both types of missions

- From a NASA perspective there is no one "right" solution between the various green propulsion systems being developed 


\section{Role of Partnerships}

- The current fiscal reality of government funding pushes technology development efforts towards more cooperative, partnership-based approaches

- With the goal of fostering partnerships and promoting collaboration where feasible, the GPWG intends to be a forum for communicating to and seeking subject matter experts, facilities, and institutional support across NASA and outside the Agency

- These partnerships include:

- Intra-NASA partnerships (i.e. between Centers and/or HQ Mission Directorates)

- Inter-Agency partnerships (i.e. between NASA and other government agencies)

- public-private partnerships (i.e. between NASA and private commercial entities)

- working with other advisory or collaborative bodies, such as technical societies (e.g. AIAA or JANNAF bodies)

- It is also recognized that international entities have a significant investment in green propulsion technologies to date

- International partnerships carry with them unique challenges (such as ITAR/Export Control restrictions) as well as opportunities

- Yet pursuing these partnerships, where permissible, can add another layer of technical exchange that enhances technology development efforts 


\section{Summary}

- The Green Propulsion Working Group has sought to lay out a roadmap and vision for future green propulsion technology development.

- This paper specifically presents an overview of that document.

- It is the intent of this group that the roadmap serve to inform and guide future investments in green propulsion technology in a manner that addresses and aligns with NASA strategic technology investment, mission needs where they can be defined, and a vision towards growth of the technology and discipline.

- Additionally, the GPWG invites other Agencies or partners to reference the roadmap for technology development programs.

- It is anticipated that the NASA Green Propulsion Roadmap will be formally published as a public NASA document by mid- to latecalendar year 2018. 